\title{
ANGEIOMATA OF THE LARYNX.*
}

By IRWIN MOORE, M.B., C.M. Edin., Surgeon to the Hospital for Diseases of the Throat, Golden Square, London.

A Study of all the Cases recorded in Literature, with Special Reference to the Question of Hamorrhage and Treatment of these Tumours.

A RECENT case, shown at a meeting of the Section of Laryngology, Royal Society of Medicine, has drawn attention to the extreme rarity of these tumours of the larynx. Lennox Browne ${ }^{1}$ has described these growths as the rarest of all benign tumours of the larynx.

\section{Statistics.}

Morell Mackenzie, ${ }^{2}$ in I 87 I, published 100 consecutive cases of benign growths of the larynx, observed by him between the years 1862 and 1870 , amongst which only one example of angeioma occurred. The only examples he found recorded amongst I 89 cases of laryngeal growths observed by others, between 1860 and 1870 , were those of Johnson and Fourniè. These two cases, however, were not true angeiomata, and are referred to separately in the latter portion of the present article under the heading of Atypical Cases.

Fauvel $^{3}$ (Paris), in 1876 , recorded that amongst 300 cases of laryngeal growths which he had collected between 1862 and I 875 , he had only observed 2 cases of angeioma.

Heinze ${ }^{4}$ (Leipzig), in I88I, refers to having found only 5 cases in the literature, and mentions 2 other cases, one of which he had observed himself, and the other upon which he had operated.

Norris Wolfenden, ${ }^{5}$ in I888, collected together 12 cases, the only ones he found recorded up to that date, which included one of his own.

Chiari ${ }^{6}$ (Vienna), in 1896 , collected 4 cases, and described one of his own. His work on Hæmangeioma of the Larynx contains the literature up to 1896 .

Jurasz $^{7}$ (Vienna), in 1898 , collected 19 cases, which included

* A paper read at the Second Annual Summer Congress of the Section of Laryngology, Royal Society of Medicine, on 25th June 1920. A full description of the Plates will be found at the end of the completed paper. 


\section{Irwin Moore}

three of his own, and he mentions that amongst I92 cases of benign growths of the larynx he had only found 3 cases.

Moritz Schmidt ${ }^{8}$ (Frankfurt) (cited by Jurasz) in his numerous observations on benign growths of the larynx found only one angeioma.

Schroetter ${ }^{9}$ (Vienna) (cited by Jurasz) also observed only I case.

Lennox Browne, ${ }^{1}$ in $\mathbf{I} 899$, stated that he had only seen 3 examples; of these he has recorded one.

Wyatt Wingrave, ${ }^{10}$ in 1906 , amongst 50 cases of benign laryngeal growths, found only I case of pure angeioma, I case of angeio-myxoma, and 9 cases of angeio-fibroma.

Phillips and Ruh ${ }^{11}$ (Cleveland, U.S.A.), in I9I3, reviewed the literature of 26 cases recorded up to this date, and added another case of their own, making 27 cases in all.

Emil Mayer ${ }^{12}$ (New York), in I9I6, brought the number up to 42 , which included I 3 recorded before 19 I 3 but overlooked by the previous authors, one recorded after publication of their papers, and another reported by himself (Mayer). He states that this is the total number recorded in medical literature.

After a thorough search of the literature, the present writer (Irwin Moore) has traced $3 \mathrm{I}$ additional cases of laryngeal angeiomata, making a total of 73 as recorded up to July 1920 . Amongst these, only two or three appear to be doubtful in character.

\section{Classification.}

I. Hæmangeioma Simplex (or Local Teleangiectasis). 2. Hæmangeioma Cavernosum. 3. Hæmangeioma Diffusum (or Teleangiectasis Diffusa). 4 Lymphangeioma. 5. Mixed or Atypical cases. These will be more fully described under Histology.

Etiology.-The atiology of angeiomata of the larynx is obscure. They are considered by some writers to be the result of a previous inflammatory condition of the mucous membrane, which has passed to the chronic stage, with hyperplasia of the tissues; such growths as fibromata and cysts are attributed to the same cause. The fact that in nearly every case there is a history of catarrh of the larynx would appear to support this view. Angeiomata are said to occur most frequently in those who abuse their voices, and some authorities consider 


\section{Angeiomata of the Larynx}

that there is a relationship between nasal obstruction and their development.

Safranek ${ }^{13}$ thinks that angeioma simplex is practically always congenital, and in later life increases in size and gives rise to symptoms, being probably overlooked in early life. He thinks that angeioma cavernosum is due to congenital anomalies of the vascular apparatus of circumscribed regions, even though there are many signs in favour of the fact that it may develop in later life.

Ribbert ${ }^{14}$ (Zurich) is also of opinion that they are always congenital, and at a later period may suddenly develop and assume rapid growth.

Brown Kelly ${ }^{15}$ and Parkes Weber ${ }^{16}$ are of opinion that the teleangiectatic form, i.e. angeioma simplex, is not congenital, and generally appears at middle age, but this view is not confirmed.

It is more than probable that the majority of these tumours are congenital in origin, a number of cases having been recorded by careful observers from the age of 9 months upwards. There appears to be very little doubt that lymphangeiomata are congenital in origin.

Appearance.-Angeiomata may be single or multiple. They are generally unilateral and single, though cases reported by Wolfenden, Hirsch, and T. R. Hamilton were bilateral. They may be associated with similar tumours in other parts of the body.

They vary in size from a lentil-seed upwards, but rarely exceed that of a filbert. They are seldom pedunculated, and generally appear merely as raised plaques.

In character they are generally of soft consistence and analogous to the ordinary nævi of the skin, and readily yield to palpation with a probe. Morell Mackenzie has described one of hard consistence.

Whilst in situ the hæmangeiomata are of a dark bluishgrey or purplish colour, and of a racemose or blackberry-like character, but after removal they are pale red or pink. In one of Lennox Browne's cases the tumour varied at times from white or pink to florid red.

In the case of the simple form the tumour is generally discovered only accidentally, and appears as a flattened elevation of bright red colour. Horn and Möller ${ }^{17}$ refer to this as a varicosed form, which occurs only in isolated cases, such as those of Schroetter, Chiari, and Imhofer. 


\section{Irwin Moore}

Age and Sex.-They may occur at any age, but most frequently are found during the middle period of life, and in the proportion of four males to one female. Phillips and Ruh, also New and Clark, have recorded the youngest cases in a boy and girl aged 9 months; Goris, in a child aged 4 years; Brady, in a boy aged 6 years, and Edmund Meyer, in a boy I 3 years of age. The oldest case has been reported by Bronner, that of a male aged 63 .

Site.-These neoplasms may be found in any part of the larynx. In the majority of cases they spring from the margin or upper surface of the true vocal cord, and next in frequency from the ventricular bands and aryepiglottic folds; but instances are recorded in which their origin was from the ventricle of Morgagni, the pyriform fossa, or the epiglottis; hence they may be classified as intra-laryngeal or extra-laryngeal.

Elsberg ${ }^{18}$ (New York), in 1884 , stated that all those tumours which had been described up to that date were situated near to the anterior commissure, and usually on the right vocal cord.

This opinion is not, however, confirmed by later records, which show that these growths are not necessarily situated near to the anterior commissure, but are much more generally distributed in the larynx, for amongst 66 cases in which the site of the growth was definitely recorded, 33 were situated on the vocal cords ( 13 on the left, II on the right; in 9 cases the affected cord was not stated, and only I I in the series were close to the anterior commissure).

Of the remaining 33 cases, 4 were on the ventricular bands; 4 originated from the ventricle of Morgagni; 2 were on the epiglottis; 4 on the aryepiglottic folds; 2 in the pyriform fossa; 6 on the arytænoid or in the inter-arytænoid region, and 4 were subglottic; 7 were of a diffuse character (in 6 cases partly originating from the vocal cord).

Symptoms.-As long as the tumour remains small there may be no symptoms. When larger, the symptoms to which they give rise are: chronic laryngitis, extending over many years, accompanied by cough, hoarseness, aphonia, difficulty in breathing, or expectoration of mucus tinged with blood. Deglutition may also be interfered with. Hæmorrhage in angeiomata of the mucous membrane occurs more readily than in angeiomata of the skin, especially if punctured or incised, and is more difficult to arrest in the former case. Serious 


\section{Angeiomata of the Larynx}

hæmorrhage may occur, as in the cases reported by Loomis and others.

Angeiomata, as previously stated, are seldom pedunculated. A few cases have been recorded by Fauvel, ${ }^{2}$ Elsberg, ${ }^{18} \mathrm{Kidd}^{26}$ Desvernine, ${ }^{27}$ etc. When pedunculated they are fairly movable, and the symptoms to which they give rise may vary very rapidly, according to whether they hang into the glottis, and therefore prevent closure of the cords, or the reverse. Consequently they may cause respiratory trouble, as in the case of Goris, and even death as a result of obstruction of the larynx, as in the case recorded by Phillips and Ruh.

Diagnosis. - They may generally be recognised by a history of bloody sputum or unaccountable hæmorrhage, which relieves for some time any hoarseness present; by their colour, and by their soft consistency, yielding readily on palpation with a probe. It is said that the remarkable colour of the growths has sufficed in all cases to distinguish them, but this is not so, for a considerable number have only been diagnosed microscopically. Rüeda (Madrid) reports having diagnosed a case of hæmangeioma by aspiration of the tumour with a hypodermic syringe, whilst Richardson (Washington) has diagnosed a lymphangeioma by puncturing it with a laryngeal knife.

The clinical recognition of these tumours is of great importance, in view of the danger of uncontrollable hæmorrhage, which may follow the removal of a portion of the growth for diagnostic purposes. Vascular papillomata, fibromata and varices are frequently erroneously diagnosed and described as angeiomata. Hirsch ${ }^{57}$ remarks that many cases of small bluish nodules on the vocal cords, without external signs of cavernous tumour, and in which no histology has been recorded, should not be regarded as true angeiomata, since they may just as well be varicosed veins, or polypi with great richness in vessels and recurring hæmorrhage. Occasionally angeiomata tend to recurrent hæmorrhages, which may be mistaken for hæmoptysis. Tuberculosis, malignant disease, and cysts of the ventricle of Morgagni, have also been mistaken for this condition. Emil Mayer records a case which was diagnosed as cancer. Shurley reports a syphilitic gumma which was mistaken for an angeioma. Cases of true cavernous angeiomata must be differentiated from lymphangeiomata (see Koschier's and Richardson's cases). 


\section{Irwin Moore}

\section{Histology.}

Hamangeioma Simplex.-This variety is constructed of a close plexus of dilated capillaries and small veins, a new formation of capillaries being one of the essential characters of the growth, the lesion being localised to a particular area. The development of new vessels is, certainly at times, traceable at the edge of minute cutaneous angeiomata, in the form of lines of proliferating endothelial cells. Although most common in the skin, its occurrence in mucous membranes is widely spread; for it has been met with on almost all mucous membranes. As regards the parts concerned in oto-rhino-laryngology, simple angeiomata have been recorded in connection with the mucosa of the mouth, tongue and gums, the hard and soft palate, and the nose; they are, however, very rare in the pharynx and larynx.

Hamangeioma Cavernosum.-In this variety the structure consists of a coarse mesh of voluminous freely intercommunicating blood-spaces, the walls of which are of fibrous tissue lined with endothelium, the whole bearing a general resemblance to the corpus spongiosum. It is the form most commonly met with in the larynx; is not infrequently pedunculated, and presents a granular or moriform surface.

The following is a microscopical description by Hubert M. Turnbull (Pathological Institute, London Hospital) of an extralaryngeal cavernous angeioma (see Plate I., Fig. I), recently removed by Norman Patterson :-

The tissue is covered by squamous epithelium, which is surmounted by a very narrow stratum lucidum. In the tissue immediately beneath this are small lymph-adenoid nodules and mucous glands.* The remainder of the tissue consists of a net of narrow fibrous trabeculæ separating very wide spaces which are full of blood. The spaces are lined by endothelium. The trabeculæ are formed chiefly of stout collagen fibres. They contain arteries and arterioles, dilated capillaries, a very few veins, a few nerves and, in places, elastic fibres and bundles of involuntary muscle. They show many small areas of infiltration with lymphocytes, plasma cells and occasional eosinophile leucocytes. The muscular fibres in some trabeculæ lie beneath the endothelium and form a circular, usually interrupted, sheath round the blood-space; in other trabeculæ they lie deeper, in

* Only mucous glands are shown in the portion of the section selected for illustration (Fig. 1). 


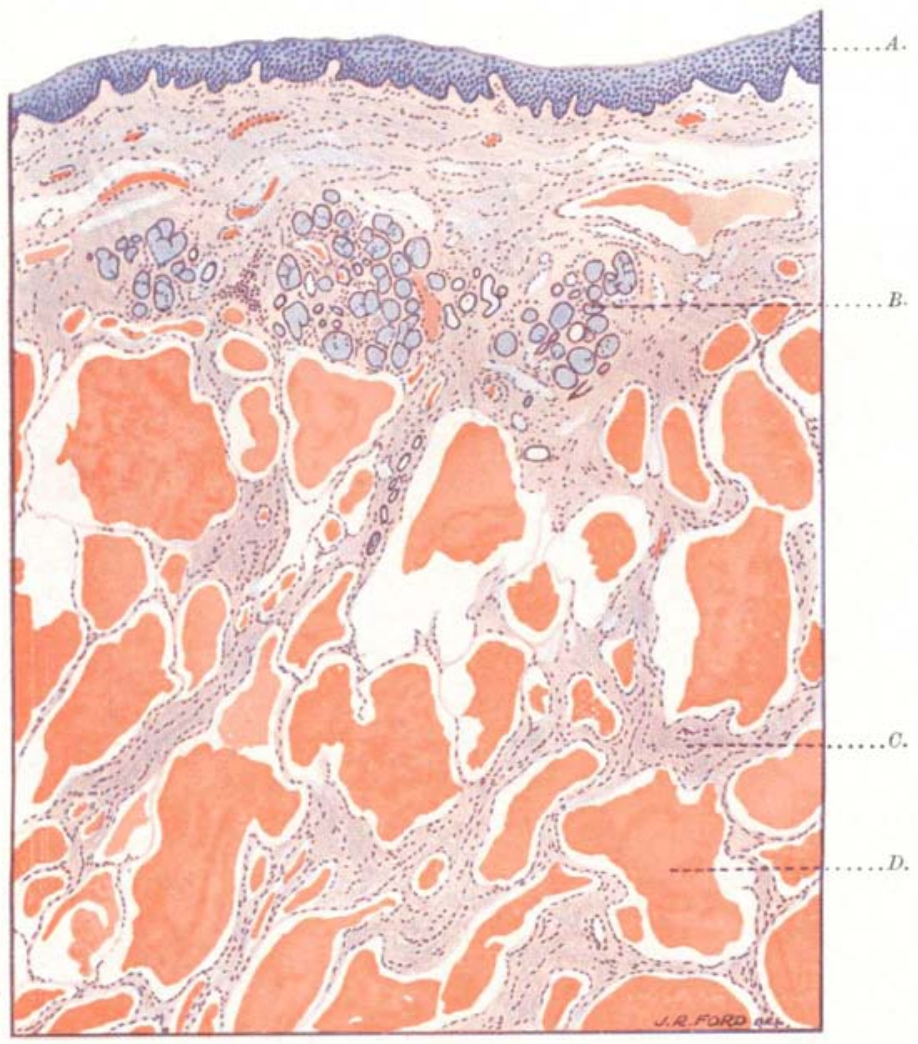

FIG. I.

Section of Angeioma Cavernosum of Left Pyriform Fossa and Aryepiglottic Fold. (Norman Patterson's Case.)

A. Surface Epithelium. C. Fibrous Tissue.

b. Mucous Glands. $\quad$ I). Blood-Clot in Cavernous Spuces,

Specially drazen for this Article from a section prepased bl. Hubert W. Turmbll-by kint permission. 



\section{Angeiomata of the Larynx}

the form of irregularly directed bundles. The elastic fibres are arranged round some of the spaces in a manner closely similar to that in the walls of veins. Superiorly, the blood-spaces reach to within a close distance of the epidermis, and there is no sharp differentiation between the spaces and dilated capillaries in this subepidermal zone, nor between the trabeculæ and the subepidermal fibrous tissue. Inferiorly, the blood-spaces terminate in an even, curved line, the stout collagenous fibres which enclose them being fairly sharply defined from the subjacent, more delicate, areolar tissue. The above characters of the structure of the tissue show that the tumour is clearly not a vascular granuloma, but that it is a true neoplasm-a cavernous angeioma composed of atypically walled veins and of capillaries.

Vitto-Massei ${ }^{53}$ has also given an excellent description along with a coloured microscopical figure of a typical cavernous angeioma which he removed.

Hamangeioma Diffusum, or Teleangiectasis Diffusa.-This form has been met with in cases recorded by Loomis, Phillips and Ruh, etc.

Safranek ${ }^{13}$ refers to it as Angeioma (or Aneurysma), Arteriale Racemosum, or Angeioma Plexiforme, the condition being due to dilatation and tortuous elongation of the whole of the arteries of some particular region.

Lymphangeioma.-The Lymphatics may likewise furnish the source of angeiomata: the new growths consisting of dilated lymph channels or spaces which are lined with endothelium and surrounded by a varying amount of connective tissue. Cases have been observed and recorded by Koschier, Richardson, and others.

Mixed or Atypical Cases consist of dilatations in preexisting normal vessels or form part of the vascular structure of a benign growth, e.g. angeio-fibroma. These have been observed and recorded by a number of observers, e.g. Johnson, Fournié, Hooper, etc.

Prognosis.-Recurrence is very rare in the case of true angeiomata.

Morell Mackenzie says there is no evidence of a tendency to recurrence, but Wolfenden refers to a case which had been under the previous care of this writer, where portions of the tissue had been removed on several occasions and had recurred. The growth was finally removed by Bond by thyro-fissure. Koschier refers to a case of lymphangeioma, which recurred a few months after removal. 


\title{
Irwin Moore
}

\author{
Abstracts of Recorded Cases of Angeiomata of the Larynx, \\ in the Chronological Order of their Report.
}

Morell Mackenzie ${ }^{1}$ described, in $1871,{ }^{*}$ the first case recorded, that of a male, aged 35 , who was seen in 1869 with a vascular tumour in the right pyriform fossa (see Plate II., Fig. 2). It was of a hard consistence, the size, colour and form of a blackberry, and was removed by evulsion with forceps in 1870 , the base of the growth being later excised with cutting forceps. Slight bleeding only took place. The growth on removal had lost its black colour, and was of a rather bright red hue. Microscopically it appeared to consist of fibrous tissue of an exceedingly close and matted character; no blood-vessels could be observed, nor did it contain any blood, but numerous elongated nuclei were seen. He refers to its appearance as corresponding with the description of a case of a venous vascular tumour removed from the thigh, and referred to by Paget. ${ }^{19}$ This case, on account of its position, cannot be strictly classified as a laryngeal growth.

Morell Mackenzie also stated that he had seen a second case in which the growth was situated on the ventricular band, but no details were recorded by him. This case is later referred to by Wolfenden, Bond, and St Clair Thomson.

Lennox Browne, ${ }^{9}$ in referring to these two cases, described the first case as doubtful, and considered that it was an example of laryngitis varicosa, as described by Lewin ${ }^{20}$ (Berlin), especially in view of the fact that it occupied the pyriform fossa, the site especially emphasised by that observer for the exhibition of this lesion.

Fauvel $^{2}$ (Paris), in 1876 , recorded a non-pedunculated cavernous angeioma of the right vocal cord in a male, aged 53 , who had suffered from hoarseness for a year, accompanied by bloody sputum. There was no difficulty in breathing. The tumour, the size of a filbert, varied in colour (in parts) from red to black, and was situated on the right vocal cord, close to the anterior commissure. It was successfully removed by evulsion with forceps, on five separate occasions-only a small amount of hæmorrhage occurring in the form of clots, which were coughed up.

The same author refers to another case in a male, aged 37 , where the growth was attached to the free edge of the left vocal cord, near

* In Morell Mackenzie's Essay on Growths in the Larynx, 1871, this growth is described under Case LXXXIX. (Appendix A., p. 188), and an excellent drawing (Plate II., Fig. 12) by Lennox Browne is shown.

Wolfenden, in tabulating the case in his article on "Angeioma of the Larynx," Journ. Laryngol. and Rhinolog., I888, II., p. 292, appears to have confused it with Case LXXXIV., Appendix D, p. 234, that of a cystic growth of the left ventricle in a physician, aged 64, seen by Morell Mackenzie in 1864 . 


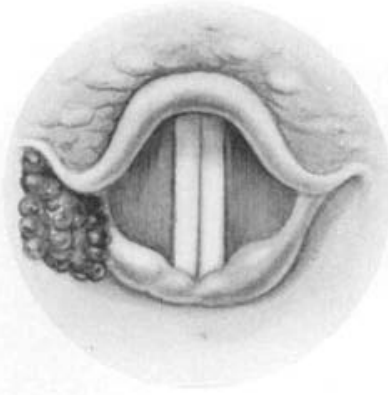

FIG. 2.

Angeioma of Pyriform liossa. (Morell Mackenzie.)

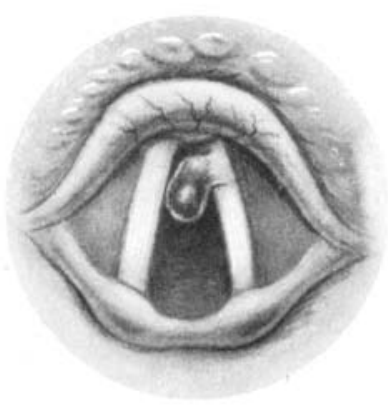

FIG. 4 .

Angeioma of Left Vocal Cord. (Percy Kidd.)

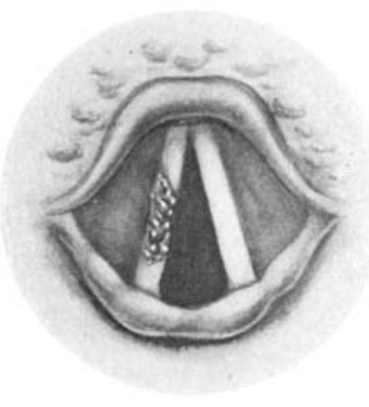

FIG. 6.

Angeioma of Right Vocal Cord. (Jurasz.)

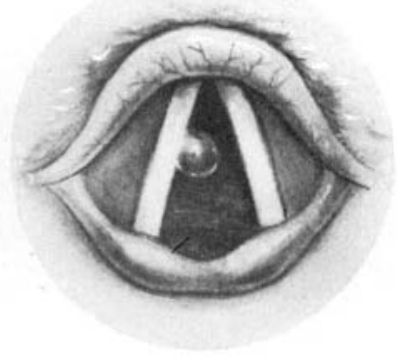

Fig. 3 .

Angeioma of Right Vocal Cord. (Solis-Cohen.)

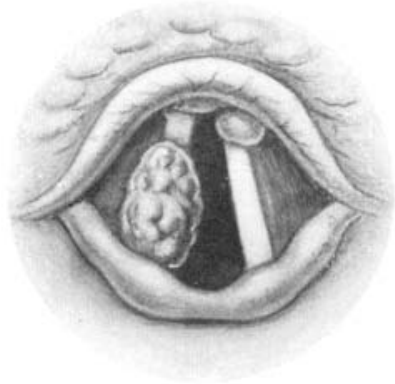

FIG. 5 .

Angeiomata of Vocal Cords. (Norris Wolfenden.)

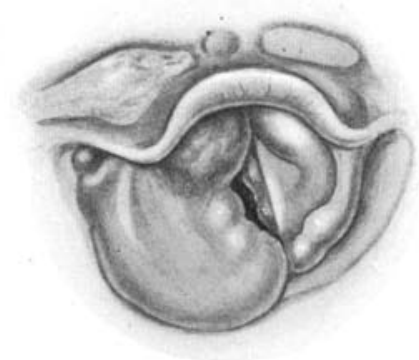

EIG. 7.

Diffuse Teleangiectatic Tumour. (St Clair Thomson.) 



\section{Angeiomata of the Larynx}

its anterior insertion. It was the size of a pea, bluish red, smooth, and slightly pedunculated. The patient suffered for seven months from severe hoarseness, with sudden attacks of aphonia. This growth was also successfully removed by forceps after four unsuccessful attempts. No bleeding occurred. Both the growths were of a soft consistence. Schwartz ${ }^{21}$ mentions a case recorded by Fauvel, aged 38 , in which "two tumours, resembling black currants, were inserted upon the ventricular mucosa near the anterior commissure." This is evidently the second case referred to above.

Coupard ${ }^{22}$ (Paris), in 1880 , reported a case of angeioma of the vocal cord, but his paper is not available.

Heintze $^{3}$ (Leipzig), in 1880 , refers to another case, a male, aged $3^{8}$, who suffered from chronic pharyngitis and laryngitis, with hoarseness of the voice. A cavernous angeioma, the size of half a lentil-seed, was found springing from the ventricle near the anterior commissure. In addition, and separated by a free space, was a second tumour of one-half the size of the former. They were both reddish black in colour, round and uneven like blackberries, and of soft consistence. Both growths were successfully removed by a galvano-cautery snare, a considerable amount of bleeding occurring during their removal.

Louis Elsberg ${ }^{18}$ (New York), in 1884 , described three cases :-

I. A cavernous angeioma, reddish brown in colour, smooth and pyriform in shape, the size of a pea, which was attached along the anterior third of the right vocal cord, very near the commissure, in a male, aged 28, who suffered from partial aphonia for four years. The tumour had existed for five years. It was successfully removed with forceps in two sittings, accompanied by severe hæmorrhage, and its base cauterised by nitrate of silver. Cure followed.

2. A similar case in a male, aged 37 . The tumour was the same size and shape, pedunculated, and attached by a thin dark pedicle to the right vocal cord near the anterior commissure. The patient had suffered from naso-pharyngeal catarrh for twelve years, and hoarseness for six years. The tumour was removed by the snare, accompanied by hæmorrhage, which was arrested by sulphate of iron. Complete cure followed.

3. A cavernous angeioma of the right pyriform fossa in a woman, aged $5^{2}$, who suffered from dysphagia, but no alteration of voice. The tumour was successfully ablated (snare or forceps not stated), but severe hæmorrhage followed, which necessitated the application of the galvano-cautery and persulphate of iron to arrest it. There was no recurrence of the growth.

Seiler ${ }^{23}$ (Philadelphia), in 1884 , recorded a case of true angeioma of the right vocal cord. No particulars are given.

Ferrari ${ }^{24}$ (Turin), in 1884 , recorded another case, in which the 


\section{Irwin Moore}

growth, the size of a hazel-nut, and of a rosy red colour, was situated beneath the edge of the left vocal cord. It was described as a "teleangiectatic tumour" of the larynx. A small piece was removed with forceps for microscopic examination; this was followed by alarming hæmorrhage, which necessitated tracheotomy and tamponnage. The patient died forty-eight hours later of inspiration pneumonia. Chiari ${ }^{5}$ has described this tumour as a teleangiectatic myxoma, and not a true angeioma.

Solis-Cohen ${ }^{25}$ (Philadelphia), in 1885 , mentions that he had seen four cases in his own practice, but he does not describe any of these cases. He remarks that angeiomata are met with most frequently at the commissure of the vocal cord, and illustrates a growth of the right vocal cord (see Plate II., Fig. 3).

Schwartz ${ }^{21}$ (Paris), in 1886 (cited by Wolfenden), referred to a submucous capillary angeioma of the larynx, but no details are given.

Percy Kidd, ${ }^{26}$ in 1888 , described the case of a woman; aged 50 , who complained of aphonia for eight or nine years and chronic bronchitis. The tumour, which was rounded, and the size of a pea, imperfectly bilobed, dark red, and finely granular like a ripe raspberry, originated from the upper surface of the left vocal cord, at the junction of the anterior and middle thirds, by a broad, flat pedicle, which allowed of considerable movement (see Plate II., Fig. 4). It was removed by means of Mackenzie's forceps in two pieces, and microscopically was shown to be a true angeioma. No bleeding of any consequence occurred.

A coloured microscopical section of this growth is illustrated in Studies in Pathological Anatomy by Wolfenden and Sydney Martin. (Plate VI., Fig. I.)

Desvernine ${ }^{27}$ (Cuba), in $\mathbf{I} 888$, recorded a pedunculated encapsulated angeioma of the epiglottis in a man, aged 53 . There was a history of occasional bleeding from the throat, the cause of which, for some time, was obscure, and on one occasion severe hæmoptysis occurred. The tumour was ovoid, lobulated, of a violet colour, measured $2 \mathrm{~cm}$. by $\mathrm{I} \mathrm{cm}$. and was attached by a pedicle to the laryngeal surface of the epiglottis. It was removed by the galvanocautery.

Wolfenden, ${ }^{4}$ in I 888 , gave particulars of a case in a male, aged 44 , who complained of slight hoarseness and recurring attacks of laryngitis, with occasional expectoration of blood. A large bright red raspberry tumour was seen upon the surface and edge of the right ventricular band, along with a similar but smaller growth on the anterior extremity of the left vocal cord, which had been present for twenty years (see Plate II., Fig. 5). This case had previously been under the care of Morell Mackenzie and other medical men, and on several occasions portions of the growth had been removed by forceps 


\section{Angeiomata of the Larynx}

and the galvano-cautery, but had recurred. [This is the case referred to by Bond in 1899 , in which he performed thyro-fissure.] In reporting this case, Wolfenden also tabulated $\mathrm{I} 2$ out of the 15 cases (which include the above case) recorded up to this date. He does not include amongst the true angeiomata the case reported by George. Johnson, ${ }^{72}$ and referred to by Morell Mackenzie, which was a vascular cyst, or the one recorded by Hooper ${ }^{76}$ (Boston), which was a vascular papilloma, similar to one previously seen by Ariza ${ }^{77}$ (Madrid), in 1887 , since neither of these were considered to be true angeiomata.

Glasgow 28 (St Louis), in 1889 , refers to the case of a male, aged 30, who suffered from persistent hoarseness for six months, and a short cough. A greyish-brown lobulated mass, the size of a large pea, was seen attached to the anterior part of the left vocal cord, a portion of the growth reaching the anterior commissure, and another portion being attached by a pedicle to the surface and edge of the left vocal cord. It was very soft, and was removed en masse with forceps under cocaine anæsthesia, only very slight hæmorrhage occurring-scarcely a small teaspoon. No recurrence.

Brown ${ }^{29}$ (cited by Phillips and Ruh), in $\mathbf{1 8 8 9}$, recorded, in a male, aged 26 , an oval-shaped vascular tumour on the left ventricular band, occupying almost its entire upper surface. It was of a uniform grey colour. The patient was not treated. The original reference could not be traced for further particulars.

Tauber ${ }^{30}$ (Denver, U.S.A.), in 1889 , recorded the case of a male, aged 42 , who had an impediment to deglutition and a defect in speech, with shortness of breath. He had been treated for two years for catarrh. A smooth, shiny, bluish-red growth covered the entire dorsal surface of the epiglottis. The interior of the laryn $x$ was not implicated to a great extent-only a chronic laryngitis. 'The tumour was removed by the galvano-cautery loop, with very slight hæmorrhage. It measured $I_{4}^{1}$ inches in length, and $\mathbf{I}$ inch in width. All symptoms disappeared, and there had been no recurrence eight years after. Microscopically, the growth proved to be an angeioma.

Loomis ${ }^{31}$ (New York), in 18 yo, reported the case of a woman, aged 62, who had a tumour as large as a walnut projecting from the left side of the tongue; another involving the left side of the pharynx, both continuous with a third mass in the neck, extending from the superior maxillary bone to the clavicle. The tumours were of a purple colour, soft, and the growth in the pharynx could be enormously increased in size by compression of the mass in the neck. The tumours were stated to have existed since birth. Later, the tumours of the tongue and pharynx increased to the size of a lemon, and the cervical tumour extended from the level of the orbit to the clavicle. The patient died from congestion of the lungs and dropsy. 


\section{Irwin Moore}

Post-mortem examination of the larynx showed two angeiomata, one the size of a large pea, projecting from the ventricle of the larynx, and the other the size of a cherry, at the lowest part of the arytenoepiglottidean fold.

This is an example of a diffuse angeioma or teleangiectasis.

Jurasz $^{6}$ (Heidelberg), in $189 \mathrm{I}$, recorded three cases.

I. A male (age not stated), with a bluish-red tumour, situated anteriorly on the left vocal cord, larger than a millet-seed, and with an uneven surface. It was destroyed by the galvano-cautery on two occasions, followed by severe hæmorrhage.

2. A male (age not stated), with a red nodule half the size of a millet-seed, situated on the anterior portion of the right vocal cord. It was destroyed by the galvano-cautery, followed by only slight hæmorrhage.

3. A female (age not stated), with a small red nodular mass, situated on the centre of the right vocal cord (see Plate II., Fig. 6). The galvano-cautery was applied, with only slight hæmorrhage.

There was complete cure in all three cases.

These cases were supposed to be congenital. (Chiari.)

Schrötter ${ }^{8}$ (Vienna), in 1892 , discussed the question of varicose veins and angeiomata in the larynx. In many cases, he says, of local circulatory disturbance he found varicosed veins on the epiglottis and aryepiglottic folds. He records a small angeiomatous nodule on one vocal cord (which side is not stated), an accumulation of small varicosed veins, from which frequent hæmorrhage occurred. $\mathrm{He}$ assumed from this case that in all probability most of the laryngeal tumours described as angeiomata are really fibromata or papillomata, very rich in vessels. He removed, on another occasion, a varicose vein the size of a pea from the left aryepiglottic fold.

Dundas Grant, ${ }^{32}$ in 1893 , recorded a case of submucous hæmorrhage from the vocal cord in a woman, aged 24. There was a history of frequently repeated hæmorrhages during four years. Latterly, a small red tumour developed on the left vocal cord. It was removed by forceps without much hæmorrhage.

Chiari remarks it is doubtful whether this was an angeioma or not.

Ramon de la Sota ${ }^{33}$ (Seville), in $\mathbf{r} 895$, reported a case of mucous polypus of the left vocal cord, which was considered to be an angeioma, but no particulars are available.

Rueda ${ }^{34}$ (Madrid), in 1896 , at the First Spanish Congress of Otology, Rhinology, and Laryngology, reported the case of a woman aged 56 , who had an angeiomatous tumour of considerable size, which occupied the right aryepiglottic fold and arytenoid. The growth was movable and of a bluish-red colour, and was diagnosed by aspiration 


\section{Angeiomata of the Larynx}

of blood with a syringe. The question of removal is not referred to in the report.

Bean $^{35}$ (U.S.A.), in 1896 , reported two cases of angeioma of the larynx. (I) A pedunculated tumour, situated at the middle of the upper surface of the right vocal cord. (2) A similar tumour on the free margin of the right vocal cord. The exact position is not stated.

Both were extirpated with forceps; no hæmorrhage is recorded, and there was no recurrence.

Chiari $^{5}$ (Vienna), in 1896 , referred to a male, aged 28 , who suffered from chronic pharyngitis and laryngitis. A round, bluish, sessile nodule, the size of a large hemp-seed, was seen in the middle of the right vocal cord. It was removed by forceps on two occasions, with "disproportionately great hæmorrhage."

Pantaloni ${ }^{36}$ (Italy), in 1897 , recorded an angeioma of the left vocal cord in a woman, aged 38 . It was removed by thyro-fissure. No further details available.

Kuttner ${ }^{3 \overline{7}}$ (Tübingen), in 1897 , wrote a paper (cited by Harmer) on "Intermittent Inflammation of Lymphangeiomata."

Ribbert ${ }^{14}$ (Zurich), in 1898 , published a paper giving original views and a consideration of the genesis of hæmangeiomata and lymphangeiomata under one heading.

Bond, ${ }^{38}$ in 1899 , described the case previously reported by Wolfenden in 1888 , and referred to the growth as a dark-bluish tumour, situated upon and covering two-thirds of the right ventricular band. Later, he performed thyro-fissure and removed the tumour. (See also reference to this case by St Clair Thomson in 1905.)

Lennox Browne, ${ }^{9}$ in 1899 , refers to a case which he had operated upon in $189 \mathrm{I}$, a male, aged 40 , who had suffered from hoarseness for two and a half years. The growth, which was small, round, smooth, and of a pink colour, was situated at the anterior commissure, had the appearance of a papilloma, and was removed by a snare. It was described as a thrombosed angeioma. Two microscopical sections of the tumour are illustrated.

Hamilton $^{39}$ (Sydney), in 1899 , recorded an angeioma of the vocal cord, in a female, aged 25. There were two growths : the larger one originated from the right cord, at the junction of its anterior and middle third, and partly from its free border and upper surface, thus interfering with complete adduction. The second growth, which was on the opposite cord, was much smaller, somewhat more posterior, and entirely on the upper surface.

The larger growth was entirely destroyed with the galvano-cautery. The smaller one was treated by the application of 20 per cent. solution of sulpho-ricinate of phenol, applied at intervals of three days. After the third application not a trace of the growth was 


\section{Irwin Moore}

to be seen. Hamilton thinks that the larger growth could have been removed in the same way.

Goris ${ }^{40}$ (Brussels), in 1899 , reported the case of a child, aged 4 years, with symptoms of hoarseness for two months, accompanied by attacks of dyspnœa. A round bluish tumour was seen almost covering the laryngeal aperture. The right vocal cord could be seen here and there intact.

Tracheotomy and thyro-fissure were performed, and the tumour removed by a snare. A fair amount of hæmorrhage occurred, which was controlled by the galvano-cautery. The tumour was found to be the size of a lentil, occupying the left ventricle of Morgagni, the wall of which it had displaced upwards, which wall had appeared laryngoscopically to be a tumour. The true tumour was proved to be a vascular angeioma.

The child died nine months later of typhus.

Seifert ${ }^{41}$ (Wurzburg), in 1900 , saw one case in a man, aged $5^{\circ}$, suffering from repeated hæmorrhages. The tumour was found to originate from the left vocal cord. No further particulars are obtainable.

Sampson Trask, ${ }^{42}$ in 1900 , described a tumour with a smooth, lobulated upper surface, attached by a broad base in the interarytenoid region, in a male aged 28 . On deep inspiration the tumour projected into the lumen of the larynx. The voice was not affected. No other details given.

Fränkel ${ }^{43}$ (Berlin), reports two cases, but details are not available.

Shurley 44 (Detroit), in 1900 , reported a case in a syphilitic subject, which was diagnosed as a gumma. The growth almost entirely encircled the lower laryngeal and upper tracheal region. During a tracheotomy the growth was unfortunately incised, and caused uncontrollable hæmorrhage, which resulted in the death of the patient.

Shurley also refers to a case of W. C. Gibson of St Louis, which is evidently an error for the case of W. C. Glasgow of St Louis, previously referred to.

Brady ${ }^{45}$ (Sydney), in $190 \mathrm{I}$, recorded a case in a boy aged 6 years, who suffered from hoarseness, dyspncea, and expectoration of blood. The tumour bled easily, and was removed under chloroform with endo-laryngeal forceps. It was the size of a cherry, deep red, and was situated below the anterior commissure of the vocal cords.

Bronner ${ }^{46}$ (Bradford), in 1902, exhibited a specimen of a pedunculated angeioma of the larynx at a meeting of the Laryngological Society of London. The patient, aged $6_{3}$, had been slightly hoarse for twenty years, during the last five years of which the hoarseness had increased. There was no dyspnœa. A large raspberry- 


\section{Angeiomata of the Larynx}

shaped growth was seen in the glottis, almost the size of a marble, only a small part of the vocal cord being seen. It probably sprung from the anterior part of the left vocal cord and was removed by forceps. Microscopically it was found to be a nævoid growth of the mucous membrane ulcerated in the centre, and had become consolidated with fibrin and exudation. The vascular channels in the deeper tissues were large and numerous.

Edmund Meyer ${ }^{47}$ (Berlin), in 1904, reported a subglottic angeioma in a boy aged 13 years. It was situated on the right vocal process, and filled the larynx sufficiently to cause great dyspncea. It was removed by laryngo-fissure and the galvano-cautery snare, and was composed of cavernous tissue and newly-formed vessels.

Biazzi 48 (Mailand, Italy), in 1905, recorded, at the Eighth Congress of the Italian Association of Laryngologists, a cavernous angeioma in a hæmophiliac, aged 42 , who suffered from hoarseness of two years' duration, and occasional dyspncea. The growth was the size and colour of a blackberry, and was spontaneously expectorated with much hæmorrhage. A second and larger growth was removed by forceps eight days later, followed by severe hæmorrhage. The hæmorrhage on each occasion was controlled by gelatin enemata.

Imhofer ${ }^{49}$ (Prague), in 1905 , reported a case which, although cited by Horn and Möller as a hæmangeioma, is recorded by Imhofer as "a hæmatoma of the vocal cord and phlebectasis."

Charters Symonds, ${ }^{50}$ in 1905 , exhibited a case at a meeting of the Laryngological Society of London ( $7^{\text {th }}$ April). The patient, a male aged 30, suffered from recurring colds and hoarseness. The growth, which was vascular, lobulated, and purple in colour, was situated on the right side of the larynx, overhanging, but not involving, the right vocal cord. The ventricular band was lost in the swelling, the anterior edge of the vocal cord being just visible on phonation. It was diagnosed as an angeioma, which had probably existed since birth, and recently been aggravated by catarrh.

St Clair Thomson, ${ }^{51}$ in a discussion on this case, referred to a patient, aged 25, whom he had first seen in 1900 , and who had frequented the Golden Square Hospital for twenty or thirty years, suffering from a bluish infiltration of the right ventricular band. $\mathrm{He}$ mentioned that this case had in the past been seen first by Morell Mackenzie, and later by Wolfenden and Bond, and that attempts had been made on many occasions to treat the case by the galvanocautery, resulting in hæmorrhage, which only occurred at these times. Later, at a meeting of the Laryngological Society, he showed a coloured drawing of the larynx (drawn in I900), and described the case as a marked example of angeioma of the larynx-not a local tumour, but as seen from the drawing a form of teleangiectasis 


\section{Irwin Moore}

beneath the mucous membrane, involving the right vallecula, the right aryepiglottic fold, both ventricular bands, and the left subglottic region (see Plate II., Fig. 7). He gave the patient's age as 30 (but if correctly reported by Bond and Wolfenden the patient's age at this time would be 57 ). He believed that the patient had not suffered from hæmorrhage (but, as recorded by Bond, repeated spontaneous hremorrhages had occurred apart from the time that the galvano-cautery was used). He was apparently not aware of the later history of the case, and that Bond had performed a thyro-fissure in 1899 .

Morell Mackenzie ${ }^{1}$ mentioned this case in $187 \mathrm{I}$, but without giving any details. He referred to the tumour as "an angeiomatous growth situated on the ventricular band."

Wolfenden $^{4}$ also published the same case in 1888 , and gave the patient's age as 44. He described the growth as a large red raspberry tumour on the surface and edge of the right ventricular band, along with a smaller growth on the anterior extremity of the left vocal cord. It had been present for twenty years, and there was a history of occasional expectoration of blood. A drawing of the larynx from this author's publication shows the appearance of the growth at that date (see Plate II., Fig. 5).

Bond ${ }^{38}$ exhibited this case at a meeting of the Laryngological Society on $4^{\text {th }}$ November 1898 , and the following description is recorded :-

The patient was aged 53, and had suffered from hoarseness for twenty-eight years. As a boy he had been accustomed to shout tremendously. He had attended Golden Square Hospital for many years under Morell Mackenzie, and had been treated with the galvanocautery. At varying intervals he had spat up blood, and when seen by exhibitor he was coughing up blood and phlegm freely.

In I899, as previously stated, Bond removed the growth by thyro-fissure, and described it as a dark-bluish tumour, situated upon and covering two-thirds of the right ventricular band. No further details were published.

A comparison of the drawing of this angeioma by Norris Wolfenden (see Plate II., Fig. 5), with its increase and extension as shown by another drawing by St Clair Thomson in 1900 (see Plate II., Fig. 7), is interesting. We have, in this case, the complete history for twentyeight years of an angeioma of the larynx from its apparent origin in 1871 to its removal in 1899 by thyro-fissure.

This case has been referred to by many writers, without any details, as a separate case recorded by St Clair Thomson, whilst it has also been recorded under the names of Morell Mackenzie, Wolfenden, and Bond as three different and separate cases.

(To be continued.) 